\title{
A rare case of narrow QRS complex tachycardia
}

\author{
L. E. Swart • Y. S. Tuininga
}

Published online: 12 November 2014

(C) The Author(s) 2014. This article is published with open access at Springerlink.com

We present the case of a 63-year-old female patient who, 2 months earlier, had been diagnosed with a severe ischaemic cardiomyopathy (left ventricular ejection fraction of $18 \%$ on cardiac MRI) due to a large semi-recent transmural left anterior descending artery infarction. She was referred to our coronary care unit because her physical condition had been declining rapidly over the previous 2 days, with her main complaint being dyspnoea on the slightest physical exertion (NYHA III). She experienced no dyspnoea at rest, nor orthopnoea, chest pain or palpitations. On admission she had a regular pulse of just over 150 beats $/ \mathrm{min}$, a blood pressure of $100 / 60 \mathrm{mmHg}$, an $\mathrm{SpO} 2$ of $100 \%$ and there were no physical signs of congestive heart failure. The ECG at presentation is shown in Fig. 1. What is your most likely diagnosis?

Intravenous adenosine bolus of up to $18 \mathrm{mg}$ did not have any effect on the rhythm and her vital signs remained unchanged. A few minutes later, and 5 min thereafter, a second and third ECG were obtained (Fig. 2). Do these change your diagnosis?

You will find the answer elsewhere in this issue.

Open Access This article is distributed under the terms of the Creative Commons Attribution License which permits any use, distribution, and reproduction in any medium, provided the original author(s) and the source are credited.

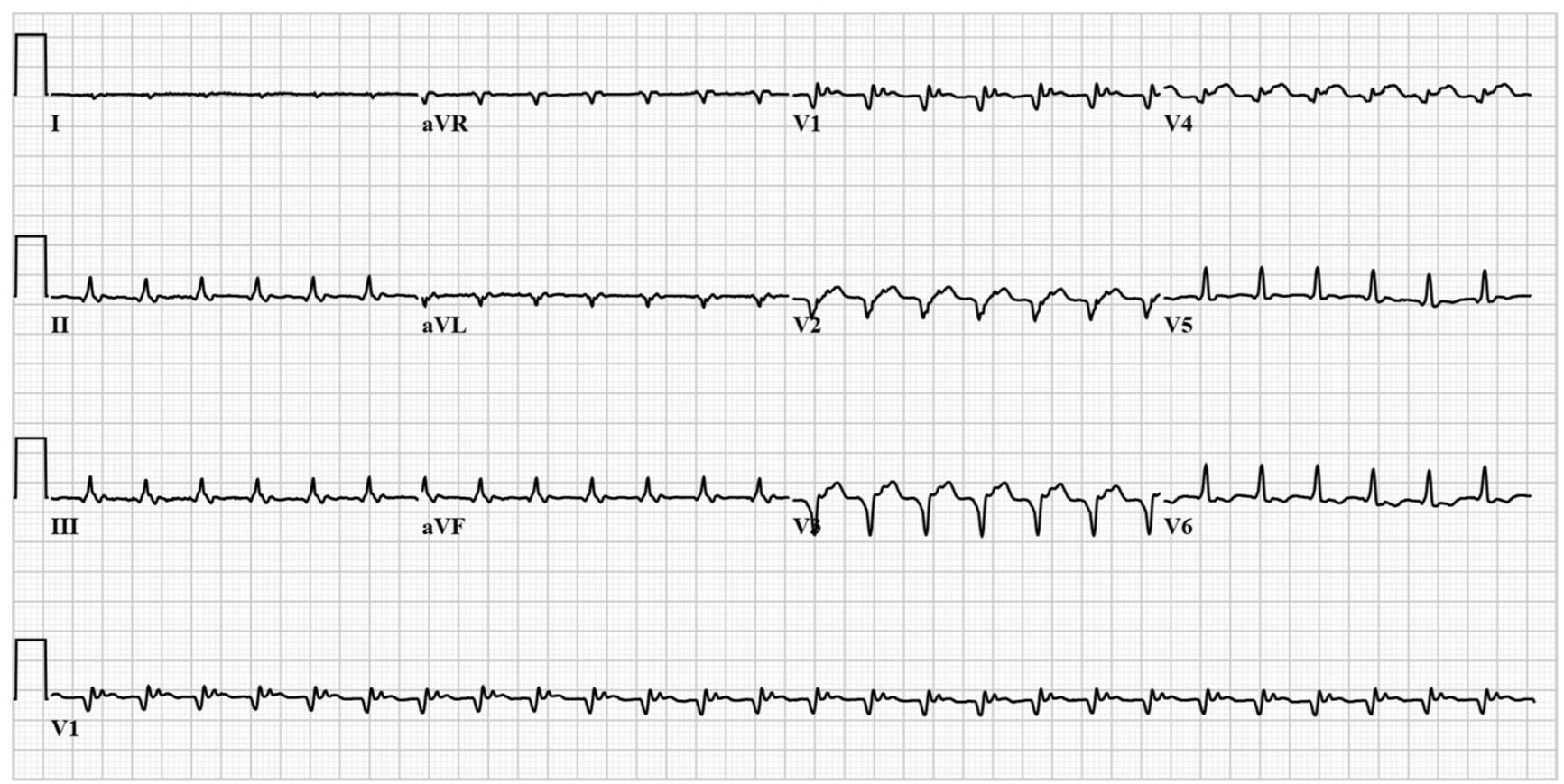

Fig. 1 First standard 12-lead ECG at presentation. Ventricular rate: $160 \mathrm{bpm}$, QRS duration (calculated): $106 \mathrm{~ms}$

L. E. Swart $(\bowtie) \cdot$ Y. S. Tuininga

Department of Cardiology, Deventer Hospital, Nico Bolkesteinlaan

75, 7416 SE Deventer, the Netherlands

e-mail: laurens.swart@gmail.com 
$\mathrm{I}_{\mathrm{I}}$

II III

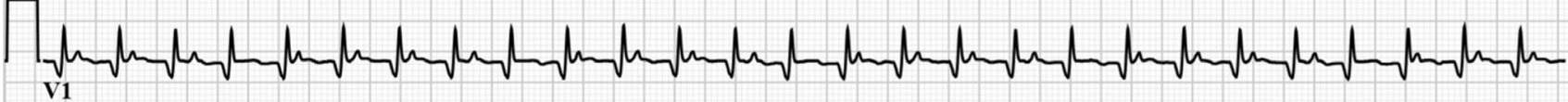

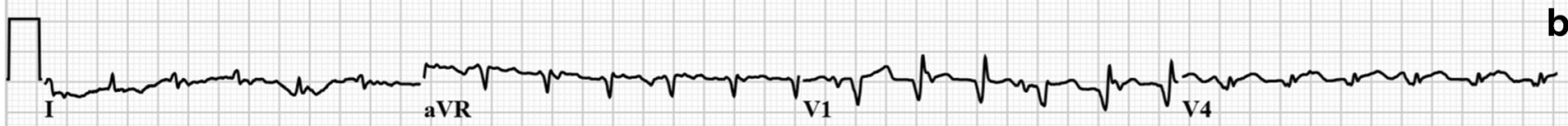
II

III

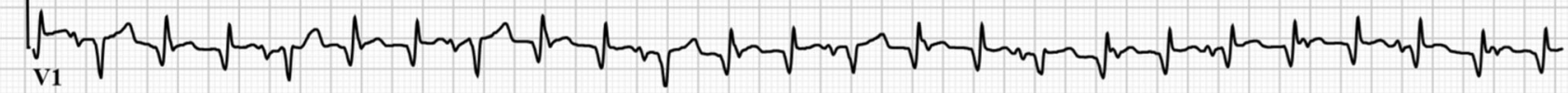

Fig. 2 a Second standard 12-lead ECG, a few minutes after adenosine infusion, and the b third standard 12-lead ECG, shortly thereafter 